\title{
Korean Prehistory: Current Perspectives
}

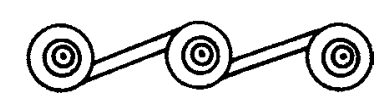

\author{
CHRISTOPHER J. BAE AND BUMCHEOL KIM
}

\section{INTRODUCTION}

DisCUSSION OF KOREAN PREHISTORY HAS TENDED TO GET LOST IN THE MIX primarily because the prehistoric records of adjacent China and Japan are better known. This is at least partly due to the fact that Korean prehistoric research got a late start vis-à-vis China and Japan. Although brief excavations were carried out during the Japanese Occupation Period (A.D. 1910-1945) by Japanese researchers at sites such as Dongkwanjin and Kulpori in the Democratic People's Republic of Korea ("North Korea”), modern Korean prehistoric research did not really take hold until the 1960s and 1970s with excavation work at important sites such as Sokchangni and Amsadong. The construction of very large dams (e.g., Chungju, Nam River) over the past several decades have also resulted in a series of major salvage archaeological excavation projects, during which sites and materials from different time periods were identified (see SeungOg Kim's article in this issue).

As a result of research conducted over the last half century, it is fairly clear that the prehistoric record of the Korean peninsula has a great deal to offer various debates in different academic fields. For instance, the discovery of bifacially worked stone implements in 1978 at Jeongok-ri (formerly transliterated "Chongokni") in deposits clearly dating to the Pleistocene renewed debate over the validity of the Movius Line (Bae 1988; Norton and Bae 2009; Norton et al. 2006; Yi 1986). Further, the identification of charred seeds in Neolithic deposits and actual cultivating fields (e.g., the Moonamri, Goseong site) indicate clearly that early and middle Holocene foragers relied on cultivated plants at least on a small scale (Crawford and Lee 2003). In Korea, dolmens appear during the Bronze Age and reach among the highest densities in the world. Thus, the analysis of dolmens provides a unique opportunity for studying the relationship between building megalithic monuments, ideological manipulation, and economic monopolization by would-be elites in the context of an increasingly complex society (Kim 2010).

Although English language texts have included or focused on the Korean archaeological record (e.g., Barnes 1993; Kim 1986; Nelson 1993) and various review papers on specific topics also exist (such as widely circulated publications on the Neolithic,

Christopher J. Bae organized this special issue on Korean prehistory. He is an Associate Professor in the Department of Anthropology, University of Hawai'i at Mānoa, Honolulu, Hawai'i, USA. Bumcheol Kim (corresponding author) is an Associate Professor in the Department of Archaeology and Art History, Chungbuk National University, Republic of Korea. 
including Ahn 2010; Choe and Bale 2002; Crawford and Lee 2003; Norton 2000a, 2007; Norton et al. 1999; Shin et al. 2012), the purpose of this special issue of Asian Perspectives is to make readily available in one location the most up-to-date and inclusive syntheses of Korean prehistory. Since we wanted this issue to focus on Korean prehistory, rather than comprehensively covering Korean historical archaeology, we have excluded research on the Proto-Three Kingdoms, Three Kingdoms, Unified Silla, Koryo, and Chosun periods. The articles in this issue range from recent developments in Korean prehistoric research to hominin paleontology and on to studies on the Palaeolithic, Neolithic, Bronze Age, and Iron Age. Although some scholars refer to the Neolithic as the "Chulmun" and the Bronze Age as the "Mumun," in order to be consistent with other works (e.g., Bae and Kim 2010; Bae et al. 2013; Kim and Bae 2010) we continue to employ the terms Neolithic and Bronze Age. This also follows the convention of most Korean scholars, who regularly refer to these cultural periods as "Neolithic" (신석기시대) and "Bronze Age" (청동기시대).

We specifically invited leading Korean scholars to contribute articles to this special issue of Asian Perspectives because many of them have primary data to synthesize and disseminate to the broader international academic community. Due primarily to constraints on accessing sites and materials from North Korea (Norton 2000b), the majority of the discussions that appear in these articles focus on the better-known record from the Republic of Korea ("South Korea"). Below, we briefly describe each of the contributions to this issue and emphasize the importance of each study to broadranging debates.

\section{RECENT DEVELOPMENTS}

In this issue, Seong-Og Kim presents a synthesis of Korean prehistoric research that has been published over the past two decades, with a particular emphasis on major topics of debate. He covers all of the major cultural periods (Palaeolithic, Neolithic, Bronze Age, Iron Age). Kim discusses three primary areas of research in the Palaeolithic section of his article: 1) Middle Palaeolithic; 2) Chronology; and 3) Subsistence. $\mathrm{He}$ also spends some time detailing various debates from the Neolithic, Bronze Age, and Iron Age. We discuss each of these in turn.

Whether a true Middle Palaeolithic is present in the region is a thoroughly discussed question that applies not only to the Korean record, but to all of eastern Asia (Gao and Norton 2002; Ikawa-Smith 1978; Norton et al. 2009). In this issue, Kim presents a nice review of the various arguments for and against the presence of a Middle Palaeolithic in Korea. Although Kim does not take a particular side in the debate, there does seem to be growing support for dividing the Korean Palaeolithic into two cultural periods (Early and Late) rather than three (Lower, Middle, Upper) (Seong 2002). Indeed, the articles on the Palaeolithic by Bae and Guyomarc'h, Lee, and Seong in this issue all use the two-stage Palaeolithic cultural sequence.

Chronology in Korean Palaeolithic research has traditionally been one of the most intensely debated topics in the field (Norton 2000b). In particular, the age of the important hand axes found in a series of sites along the Imjin-Hantan River Basins (IHRB) in Gyunggi Province has ranged from the middle of the middle Pleistocene to the latter half of the late Pleistocene (Bae 1988; Bae et al. 2012; Danhara et al. 2002; Norton and Bae 2009; Norton et al. 2006; Yi 1986, 2010; Yi et al. 1998; Yoo 2007). How to date the soil wedges that are found in many open-air archaeo- 
logical sites in Korea is an important topic described in some detail by Seung-Og $\mathrm{Kim}$ in this issue. A better understanding of these two important issues would contribute to a better chronological framework for many of the Palaeolithic sites in Korea, particularly those that have exposed archaeological materials (i.e., hand axes from the IHRB) that are important for addressing broader ranging debates (see discussion below).

Seung-Og Kim suggests Cho (2005) is the most active Palaeolithic zooarchaeologist in Korea. Cho (2005) follows a long line of Korean faunal analysts (e.g., Lee 1984, 1994; Sohn 1980) that have attempted to make sense of the Pleistocene vertebrate palaeontological fossils that were excavated from a series of cave sites in the central region of South Korea, namely Turubong, Chommal, and Kunanggul. In general, these faunal analysts have assumed that these cave sites served as hominin home bases and that the presence of the faunal remains are primarily the result of hominin hunting and transporting carcasses for processing. These same researchers have suggested that these hominins used bone tools, which to them readily explains the absence of stone tools. Further, these analysts suggest that the hominins from sites such as Turubong, Chommal, and Kunanggul created bone art. It should be noted that, based on firm modern-day vertebrate taphonomic methodological and theoretical grounds, a few other researchers (e.g., Bae 2013; Norton 2000b) have raised serious questions about the interpretations made by Lee (1984, 1994), Sohn (1980), and Cho (2005).

As Seung-Og Kim observes, subsistence reconstructions have sharply increased in Korean Neolithic archaeology since the early 2000s (e.g., Crawford and Lee 2003; Lee 2002; Norton 2000a, 2007). Zooarchaeologists and archaeobotanists have led this move; most of their studies have explicitly or implicitly aimed at explaining the transition to agriculture. Unfortunately, biological residues do not last very long once buried due to acidic soils in most Korean contexts. As a result, attempts to describe the advent of agriculture in Korea often rely on isolated finds; these take on added significance due to the paucity of similar data in the record (i.e., cultivating field plots or charred grains within dwellings). As a matter of fact, new finds such as large settlements and cemeteries in the coastal regions, active cultivating fields that may be among the earliest in eastern Asia, and the discovery of an actual Neolithic deep seafaring boat have forced Korean prehistory specialists to rethink traditional views of Neolithic society as composed of simple egalitarian hunter-gatherers.

Over the past decade or so, the number of specialists in Bronze Age archaeology has increased dramatically in Korea, which in turn has resulted in the development of a broader range of research avenues. The majority of recent Bronze Age studies have focused on topics such as the origin and nature of complex social organization, development and mobilization of surplus, and economic specialization or intensification. Seung-Og Kim concentrates his discussion on the Korean Bronze Age primarily on issues of chronology. However, other Bronze Age debates, some of which are discussed by Bumcheol Kim in this issue, do exist and are closely related to chronological issues. For instance, an intense debate on the development of leadership strategies during the Middle Bronze Age began with a critique of an explanatory scheme for the indigenous origins of the Songgukri-type assemblages, which are located along the middle reaches of the Geum River basin. Proponents of the indigenous-origin model hypothesized that the emergence of the Songgukri-type settlements resulted from people gathering to jointly perform labor-intensive wet-rice agriculture in the area, 
whereupon political leadership developed to organize labor effectively (e.g., Kim 2003, 2008). This explanation is compatible with a managerial leadership model founded on an adaptational perspective. Nevertheless, distributional patterns of factors relevant to wet-rice cultivation, particularly with reference to regional-scale settlement systems, do not support the indigenous-origin model (Kim 2005a, 2014). Not surprisingly, proponents of so-called "outside models" welcomed alternative explanations (e.g., Lee 2005).

In Korea, the Iron Age is characterized by jeomtodaetogi (rolled-rim pottery) and the slender bronze dagger represents a transition to historical times, where written historical texts contribute to archaeological reconstructions. In this volume, Seung-Og Kim notes that recent discussions about the transition to the Iron Age have been grounded in anthropological archaeology rather than in a traditional culture history approach.

Having illuminated some general theoretical trends in Korean archaeology, we would also like to briefly review some of the important new methodologies and interpretative frameworks in Korean archaeology for each period highlighted in the articles in this special volume.

\section{Hominin Palaeontology}

The origin of modern humans continues to be an intensely debated topic in palaeoanthropology. Traditionally, the late Pleistocene eastern Asian hominin fossil record has been used to support various versions of the multiregionalism, replacement, or assimilation models (Norton and Jin 2009; Trinkaus 2005). In this issue, Christopher Bae and Pierre Guyomarc'h present an analysis of two relatively intact hominin crania from the important Ryonggok cave site in North Korea (Bae 2010; Norton 2000b). The Bae and Guyomarc'h study in this issue is potentially important because, outside of the two best-known late Pleistocene sites from China (i.e., Zhoukoudian Upper Cave, Tianyuandong), hominin cranial fossils are not well known in the region (Norton and Jin 2009). The primary result of Bae and Guyomarc'h's study is that the Ryonggok fossils appear to be more similar to Late Palaeolithic human foragers rather than an older hominin taxon (e.g., Homo erectus, mid-Pleistocene Homo) and more recent Holocene modern humans. Thus, the Ryonggok humans add to a growing list of late Pleistocene fossils from, for example, Lunadong (Bae et al. 2014) and Huanglongdong (Liu et al. 2010). This suggests that modern humans likely were in the region earlier than might be anticipated by the original definition of the replacement hypothesis. More detailed field and laboratory research, particularly at sites such as Ryonggok in North Korea, are critical to developing a better understanding of a very complex picture of human evolution in the region.

\section{Early Palaeolithic}

Early Palaeolithic sites were clearly identified in South Korea beginning in the 1960s with the discovery and excavation of Seokjang-ri (Norton 2000b). Following the discovery of bifacially worked implements at Jeongok-ri in 1978 and subsequent fieldwork in the region over the past several decades, discussion of the Korean Early Palaeolithic concentrated on the meaning of hand axes discovered east of the Movius Line (Norton et al. 2006). Indeed, these Early Palaeolithic sites and materials along 
the Imjin-Hantan River Basins (IHRB) formed the foundation for a series of doctoral dissertations at North American universities (Bae 1988; Yi 1986; Yoo 2007). In this issue, Hyeong Woo Lee discusses the Korean Early Palaeolithic from a more theoretical perspective. As with Seung-Og Kim's contribution, Lee describes the Middle Palaeolithic in Korea and concludes that a two-stage cultural sequence is probably most suitable for the Korean Palaeolithic as it is in China (Gao and Norton 2002; Norton et al. 2009). Lee does not go into great detail about many of the important Early Palaeolithic sites outside of Jeongok-ri or major topics of debate other than on the IHRB hand axes. Interested readers are therefore urged to see discussions that appear in various other publications in the English language (i.e., Bae 2013; Bae 1992; Norton 2000b; Norton et al. 2006; Seong 2004; see also S.-O. Kim this issue). Fortunately many interesting ongoing debates concerning the eastern Asian Early Palaeolithic include discussion of the Korean record (Lycett and Bae 2010; Lycett and Norton 2010; Norton and Bae 2009; Norton et al. 2006).

\section{Late Palaeolithic}

In this issue, Chuntaek Seong notes that the vast majority of Palaeolithic sites in Korea are currently assigned to the Late Palaeolithic. In addition to a detailed discussion of the Middle Palaeolithic and why there is little to no evidence for it in Korea (see also Gao and Norton 2002; Hyeong Woo Lee in this issue), Seong here focuses on stone tool types to present a detailed discussion of the Late Palaeolithic period in Korea (see also Bae and Bae 2012; Norton et al. 2007; Seong 1998, 2007). Archaeologists have traditionally interpreted the appearance of blade and then microblade technologies as signaling the advent of the Late Palaeolithic in much of eastern Asia (Gao and Norton 2002). Seong in this issue and others such as K. Bae (2010) and Bae and Bae (2012) have noted that blade and microblade technologies did not simply sweep across the peninsula, replacing Early Palaeolithic core and flake tools. Rather, after c. 40,000 year ago, blades appear sporadically, followed by microblades c. 30,000 years ago in the archaeological record. Two important points are raised by Seong here: blades and microblades only begin to become a major component of the stone tool industries in Late Palaeolithic Korea after 30,000 years ago; and in addition to blades, tanged points also appear early on and should be considered another signal of the transition from the Early to Late Palaeolithic in the region. Besides the detailed review and presentation of the most relevant sites in the Korean Late Palaeolithic, Seong here places the Korean record in broader regional context by using a comparative approach.

\section{Neolithic}

In this issue, Sung-Mo Ahn, Jangsuk Kim, and Jaehoon Hwang argue that the smallscale millet cultivation that appears during the Neolithic did not lead directly to the extensive widespread agricultural economy that took hold with the advent of the Bronze Age. Finding problems with models that premise increasing sedentism to explain increased reliance on cultivated plants, Ahn, Kim, and Hwang suggest that current dwelling and settlement data indicate that the number and size of sedentary villages actually decreased from the Middle to Late Neolithic. In their view, environmental deterioration played a more significant role in these cultural changes during the Neolithic. At the same time, based primarily on questions related to 
archaeobotanical provenance, Ahn, Kim, and Hwang disagree with arguments that rice was adopted and cultivated since the Middle or Late Neolithic.

Nevertheless, small sample sizes in their study may prohibit drawing a firm conclusion regarding whether these types of data can be used to address the origin of agriculture in Korea. In order to fully address the question of agricultural origins in Korea using settlement data, it might be worthwhile to also examine comparable data from the very early part of the Bronze Age. Settlement data from the early Bronze Age indicate many similarities with the Middle and Late Neolithic. For example, Incipient Bronze Age settlements are also relatively small, not very numerous, and are located in the same locations (i.e., along rivers) as Neolithic settlements. Is this evidence of an indigenous cultural change or new populations migrating into the region and settling in the same areas? The picture becomes noticeably different once moved fully into the Bronze Age, when full-scale wet-rice agriculture really took hold. Because Ahn, Kim, and Hwang do not evaluate any specific case to test their hypothesis that all archaeobotanical identifications of rice at Neolithic sites are suspect, it is a little premature to draw any firm conclusion regarding this point. The development of agriculture in Korea will continue to be a hotly debated topic. Fortunately, studies such as theirs contribute to developing a better understanding of the debate.

\section{Bronze Age}

Currently, the transition from the Early to Middle Bronze Age in South Korea is thought to have been related to a series of socioeconomic changes. Keen interest in evaluating the nature of these socioeconomic changes during the Korean Bronze Age has resulted in a number of doctoral dissertations at British and North American universities since the mid-2000s (Bale 2011; Choi 2011; Kim 2005b; Koh 2008; Woo 2009). Using a comparative archaeological approach to evaluate social complexity (Smith 2012), Bumcheol Kim in this issue examines the transition in terms of changes in social organization, household composition and activities, production and distribution of agricultural products, craft specialization, mortuary practice, and symbolic activities. Further, Kim offers an extended discussion on two crucial issues in Korean Bronze Age archaeology: varying elite strategies for agricultural intensification; and the factors involved in deciding household size and composition as an adaptive strategy, particularly of primary producers.

\section{Iron Age}

The cultural period characterized by the slender bronze dagger and jeomtodaetogi (rolled-rim pottery) has been called different names by different scholars: early part of the Late Bronze Age, Early Iron Age, Iron Age, and sometimes Samhan period. Although there has not been much disagreement about what the material culture looks like from this cultural period, as Kisung Yi notes in this issue, the period has gone largely undefined.

The Iron Age has not been as intensively researched as other cultural periods in Korea largely because few major discoveries were identified until the 2000s. Indeed, settlement sites with more than ten individual dwellings were not excavated until recently. Fortunately, recent excavations of large and ditched settlements have allowed archaeologists the opportunity to rethink the relationship between the Middle Bronze 
Age and Late Bronze Age or Early Iron Age cultures. Previously, it was assumed that the group with jeomtodaetogi assemblage was an immigrant group that was absorbed into the native groups represented by Songgukri-type pottery. Yi here also notes that there is an almost 100-year time lag between the emergence of the Jeomtodaetogi Culture and the adoption of various bronze objects from the so-called dongbei (東北) region in northeast China. This observation was originally suggested in the early 2000s (Kim 2001) and now seems to be broadly accepted. Yi suggests in this issue that this century-long time lag may be the result of trying to use a combination of historical and archaeological approaches to addressing debates in late prehistory, where historical records overlap somewhat (Kim 2001). Only further research will be able to clarify what the true meaning of this 100 -year time lag may be.

\section{CONCLUSION}

The purpose of this special issue is to bring together a collection of syntheses of the Korean prehistoric record from leading scholars in the field, all of whom are contributing to or have access to the most recent studies in their areas of research. It is quite clear from reading these articles that the Korean prehistoric record is much better known than it was thirty, twenty, or even ten years ago. The great deal of data that are now readily available contribute to a variety of research avenues not only within Korea, but comparatively with other areas of eastern Asia, as well as to debates current in prehistoric research generally.

We anticipate that one of the major contributions of this issue of Asian Perspectives will be to list all the most important recent published research related to the major cultural periods of Korean prehistory in a single repository, readily available to researchers and students alike. Besides facilitating individual research, this special issue will be a perfect addition to future courses in eastern Asian prehistory. Further, the hundreds of references that appear in this volume will allow people interested in exploring these research topics to delve further into various debates in Korean prehistory, particularly in its broader regional comparative perspective. We invite readers to explore more deeply the articles that appear here and the various contributions Korean prehistory can make to addressing broader ranging debates in these academic fields.

\section{ACKNOWLEDGMENTS}

We would like to sincerely thank Laura Junker for the invitation to organize this special issue on Korean prehistory and for all of her editorial work to get the volume completed in a timely manner.

\section{REFERENCES CITED}

Ahn, Sung-Mo

2010 The emergence of rice agriculture in Korea: Archaeobotanical perspectives. Archaeological and Anthropological Sciences 2(2):89-98.

BAe, Christopher J.

2010 The late middle Pleistocene hominin fossil record of eastern Asia: Synthesis and review. Yearbook of Physical Anthropology 53:75-93.

2013 Paleolithic cave home bases, bone tools, and art and symbolism: Perspectives from Korea. Hoseo Archaeology 29 : 59-85. 
Bae, Christopher J., and Kidong Bae

2012 The nature of the Early to Late Paleolithic transition in Korea: Current perspectives. Quaternary International $281: 26-35$.

Bae, Christopher J., And J. C. Kim

2010 The Late Paleolithic-Neolithic transition in Korea: Current archaeological and radiocarbon perspectives. Radiocarbon 52:493-499.

Bae, C. J., W. Wang, Z. X. Zhao, S. M. Huang, F. Tian, and G. J. Shen

2014 Modern human teeth from Late Pleistocene Luna Cave (Guangxi, China). Quaternary International 354 : 169-183.

BAe, K. D., C. J. Bae, And J. C. Kim

2013 Reconstructing human subsistence strategies during the Korean Neolithic: Contributions from zooarchaeology, geosciences, and radiocarbon dating. Radiocarbon 55:1350-1357.

BAe, K. D., C. J. Bae, And K. R. Kim

2012 The age of the Paleolithic handaxes from the Imjin-Hantan River Basins, South Korea. Quaternary International $281: 14-25$.

BAE, KIDONG

1988 The Significance of the Chongokni Stone Industry in the Tradition of Paleolithic Culture in East Asia. Ph.D. diss. University of California, Berkeley.

1992 Pleistocene environment and Paleolithic stone industries of the Korean Peninsula, in Pacific Northeast Asia in Prehistory: 13-23, ed. C. M. Aikens and S. N. Rhee. Pullman: Washington State University Press.

2010 Origin and patterns of the Upper Paleolithic industries in the Korean Peninsula and movement of modern humans in East Asia. Quaternary International 211:103-112.

BALE, MARTiN

2011 Storage Practices, Intensive Agriculture, and Social Change in Mumun Pottery Period Korea, 2903-2450 Calibrated Years B.P. Ph.D. diss. University of Toronto.

BARNES, GINA L.

1993 China, Korea and Japan: The Rise of Civilization in East Asia. New York: Thames \& Hudson.

Cho, TAe-SoP

2005 Taphonomy and the Fauna of Paleolithic Korea. Seoul: Hyean (in Korean).

Choe, C., ANd M. T. Bale

2002 Current perspectives on settlement, subsistence, and cultivation in prehistoric Korea. Arctic Anthropology 39:95-121.

CHOI, Won

2011 Emergence of Agricultural Society: A Chronological Review of the Early and Middle Bronze Age on the Korean Peninsula. Ph.D. diss. University of California, Davis.

Crawford, G. W., and G. Lee

2003 Agricultural origins in the Korean Peninsula. Antiquity 77:87-97.

Danhara, T., K. D. Bae, T. Okada, K. Matsufuji, and S. H. Hwang

2002 What is the real age of the Chongokni Paleolithic site?, in Paleolithic Archaeology in Northeast Asia: 77-116, ed. K. D. Bae and J. C. Lee. Yeoncheon County and The Institute of Cultural Properties, Seoul.

GaO, X., AND C. J. Norton

2002 Critique of the Chinese "Middle Paleolithic.” Antiquity 76:397-412.

IкAWA-Sмiтн, F.

1978 Introduction, in Early Paleolithic in South and East Asia: 1-10, ed. F. Ikawa-Smith. The Hague: Mouton.

KIM, BuMCHEOL

2001 A study of Late Mumun society in southern Korea: Suggestions for future research in the Seoul region. The Journal of Seoul Studies 16:1-44 (in Korean with English abstract).

$2005 a$ The emergence of Songgukri-type settlements and agricultural intensification in the lower reach of Geum River: With reference to analysis on the spatial correlation between regional settlement hierarchy and soils using GIS, in Culture System of Agricultural Societies: Songgukri Culture: 84-119, ed. Institute of Archaeology and Environment, Korea University. Seoul: Seogyoung (in Korean).

2005b Rice Agricultural Intensification and Sociopolitical Development in the Bronze Age, Central Western Korean Peninsula. Ph.D. diss. University of Pittsburgh, PA. 
2010 Socioeconomic function of Hoseo dolmens. Journal of the Korean Ancient Historical Society 68: 5-24 (in Korean with English abstract).

2014 Understanding changes of domestic storage patterns in the Bronze Age, Hoseo region. Journal of the Korean Ancient Historical Society 83:53-68 (in Korean with English abstract).

KIM, JANGSUK

2003 The development of the Songgukri assemblage in the Chungcheong area. Journal of the Korean Archaeological Society 51:33-55 (in Korean with English abstract).

2008 Socioeconomic implications of storage facilities of the Songgukri period. Journal of the Korean Archaeological Society 67:4-39 (in Korean with English abstract).

Kim, J. C., ANd Christopher J. BAe

2010 Radiocarbon dates documenting the Neolithic-Bronze Age transition in Korea. Radiocarbon $52: 483-492$.

KIM, W. Y.

1986 Art and Archaeology of Ancient Korea. Seoul: Taekwang Publishing.

Ko, ILHONG

2008 Constructing Bronze Age Lives: Social Reproduction and the Construction and Use of Dolmen Burials from the Yongdam Complex in Jinan, Southern Korea. Ph.D. diss. University of Sheffield, UK.

LeE, HoNG-JONG

2005 The cultural contact and change in Songgukri Culture. Journal of Korean Ancient Historical Society $48: 29-50$.

LEE, JUNE-JEONG

2002 Functional variation of shell midden patterns in southern Korea. Journal of the Korean Archaeological Society $46: 53-80$.

LEE, Yung-Jo

1984 Early Man in Korea (II). Seoul: Tamgu-Dang Publishing.

1994 Paleontological and archeological remains from Turubong Cave Complex in Korea, in Paleolithic Culture of East Asia: 91-130, ed. K. D. Bae. Seoul: National Research Institute of Cultural Properties (in Korean).

Liu, W., X. Z. Wu, S. W. Pei, X. J. Wu, and C. J. Norton

2010 Huanglong Cave: A late Pleistocene human fossil site in Hubei Province, China. Quaternary International $211: 29-41$.

Lycett, S. J., AND C. J. BAE

2010 The Movius Line and Old World Palaeolithic patterns: The state of the debate. World Archaeology $42: 521-544$.

LyCETT, S. J., AND C. J. NORTON

2010 A demographic model for Palaeolithic technological evolution: The case of East Asia and the Movius Line. Quaternary International 211:55-65.

NeLson, S. M.

1993 The Archaeology of Korea. Cambridge: Cambridge University Press.

Norton, C. J.

$2000 a$ Subsistence change at Konam-ri: Implications of the advent of rice agriculture in Korea. Journal of Anthropological Research 56(3):325-348.

$2000 \mathrm{~b}$ The current state of Korean paleoanthropology. Journal of Human Evolution 38:803825.

2007 Sedentism, territorial circumscription, and the increased use of plant domesticates across Neolithic-Bronze Age Korea. Asian Perspectives 46:133-165.

Norton, C. J., And K. D. BAE

2009 Erratum to "The Movius Line sensu lato (Norton et al., 2006) further assessed and defined" J. H. Evol. 55 (2008) : 1148-1150. Journal of Human Evolution 57:331-334.

Norton, C. J., K. D. Bae, J.W.K. Harris, and H. Y. Lee

2006 Middle Pleistocene handaxes from the Korean Peninsula. Journal of Human Evolution 51:527536.

Norton, C. J., K. D. Bae, H. Y. Lee, and J.W.K. Harris

2007 A review of Korean microlithic industries, in Origin and Spread of Microblade Technology in Northern Asia and North America: 91-102, ed. S. Keates, Y. Kuzmin, and C. Shen. Vancouver: Archaeology Press. 
Norton, C. J., X. Gao, and X. W. Feng

2009 The criteria defining the East Asian Middle Paleolithic reexamined, in Sourcebook of Paleolithic Transitions: Methods, Theories, and Interpretations: 245-254, ed. M. Camps and P. R. Chauhan. Dordrecht: Springer Press.

Norton, C. J., AND J. Jin

2009 The evolution of modern humans in East Asia: Behavioral perspectives. Evolutionary Anthropology $18: 247-260$.

Norton, C. J., B. M. Kim, and K. D. BaE

1999 Differential processing of fish during the Korean Neolithic: Konam-ri. Arctic Anthropology $36: 151-165$.

SeOng, Chuntaek

1998 Microblade technology in Korea and adjacent Northeast Asia. Asian Perspectives 37:245-278.

2002 The relevance of the Middle Paleolithic concept in Korea: A critical review. Journal of the Korean Archaeological Society 46:5-28.

2004 Quartzite and vein quartz as lithic raw materials reconsidered: A view from the Korean Paleolithic. Asian Perspectives $43: 74-91$.

2007 Late Pleistocene microlithic assemblages in Korea, in Origin and Spread of Microblade Technology in Northern Asia and North America: 103-114, ed. S. Keates, Y. Kuzmin, and C. Shen. Vancouver: Archaeology Press.

Shin, S. C., S. N. Rhee, and C. M. Aikens

2012 Chulmun Neolithic intensification, complexity, and emerging agriculture in Korea. Asian Perspectives $51: 68-109$.

Smith, Michael ERnest, ed.

2012 The Comparative Archaeology of Complex Societies. New York: Cambridge University Press.

SoHN, P. K.

1980 Jeommal Cave Excavation Report. Seoul: Yonsei University Museum.

Trinkaus, E. T.

2005 Early modern humans. Annual Review of Anthropology 34:207-230.

WoO, Jung-Youn

2009 Power and Social Change in Korean Middle Bronze Age Mortuary Practice: Burials, Houses, and Contexts. Ph.D. diss. University of Cambridge, UK.

Yi, SEONBOK

1986 Lower and Middle Paleolithic of Northeast Asia: A Geoarchaeological Review. Ph.D. diss. Arizona State University.

2010 Problem of Korean Paleolithic study and age dating of basalt from Imjin River Basin. Society of Korean Paleolithic Archaeology $22: 3-20$.

Yi, S., F. ARAi, AND T. SODA

1998 New discovery of Aira-Tn ash (AT) in Korea. Journal of the Korean Geographical Society $33: 447-454$.

Yoo, Y.

2007 Long-term Changes in the Organization of Lithic Technology: A Case Study from the ImjinHantan River Area, Korea. Ph.D. diss. McGill University, Montreal.

\section{ABSTRACT}

This volume dedicated to Korean prehistory is a synthesis of current research by Korean scholars working in the areas of palaeoanthropology and Palaeolithic, Neolithic, Bronze Age, and Iron Age archaeology. Here we introduce this special volume by helping to place each of the contributions in broader perspective. One of the key contributions we anticipate resulting from this volume is that interested readers (both students and senior researchers alike) will now be able to go to one place to learn about recent research avenues in Korean prehistoric studies. Keywords: Pleistocene, Holocene, Korea; prehistory, chronology. 